\title{
Dangerous Food Items
}

\author{
Arun Singh ${ }^{1 *}$ and Arshiya Masood Siddiqui ${ }^{2}$ \\ ${ }^{1}$ Department of Community Medicine, Bareilly International University, India \\ ${ }^{2}$ Department of Community Medicine, Government Medical College, India
}

*Corresponding author: Arun Singh, Editorial board member of Journal of Gut and Gastroenterology (GG), Professor, Department of Community Medicine, Rohilkhand Medical College \& Hospital, Bareilly International University, Uttar Pradesh, PIN-243006, India

Submission: June 02, 2018; Published: June 25, 2018

\section{Introduction}

There are strong evidences linking consumption of the food products/items to increased incidences of specific cancers in the various organs and body parts of the humans $[1,2]$. There are some everyday foods and drinks that are labelled as carcinogenic as these food products/items surely contain some natural toxins, adulterants, artificial colourants, additives, preservatives, and residues of insecticides or many other unwanted/unavoidable chemicals/ ingredients [2]. These foods can cause cancer if taken for long duration and these items are processed meats (i.e. any meat that has been preserved by curing, salting or smoking, or by adding chemical preservatives) sausages, hot dogs, pepperoni, alcoholic beverages, salted fish, burned or heavily barbecued foods, red meat including, mutton, pork, lamb, hot beverages $\left(>65^{\circ} \mathrm{C}\right)$, polluted air and water $[1,2]$.

Following are the food items containing carcinogenic ingredients [1,2]:

According to the International Agency for Research on Cancer (IARC) [3] there are four primary types of potentially carcinogenic compounds are responsible for cancers in human beings.

\section{A. IARC-Carcinogenic to humans: Salted fish}

B. IARC-Possible carcinogenic to humans: Acetaldehyde and heavy alcohol consumption.

C. IARC-Probably carcinogenic to humans: Acrylamide is created in the process of high temperature during cooking of certain foods such as potatoes and cereals.

D. IARC-Possibly carcinogenic to humans: Pickled vegetables may contain mutagens and there are risks of oesophageal cancers in pickled vegetable consumers

The most famous source of aflatoxin is Aspergillus flavus that can infect peanuts, but also infects tree nuts and grains. Animals eating infected foodstuffs can produce animal food-products that contain aflatoxins. Women consuming infected foodstuffs can pass on aflatoxin to infants through breast milk. Carcinogenicity of aflatoxins in rodents, primates and fish. Humans may develop Hepa tocellular carcinoma. Alcoholic beverages of all types (fermented and those further distilled) can cause cancer in humans. Fusarium moniliforme is a species of fungus produces a series of toxic metabolites known as fumonisins, the best studied being fumonisin B1. This fungus is most closely associated with maize. DDT/DDE are the popular insecticides and its exposure can cause cancers at any site of human body $[4,5]$.

\section{Hydrogenated Oils [6]}

Hydrogenated oils with trans-fats are the worst type of fats. These are known to cause cancer, heart disease, and immune system problems. The coconut, palm and olive oils and organic butter are good for health and are better options.

\section{French Fries/Potato Chips [7]}

These fast foods contain acrylamide, pesticide residue, hydrogenated vegetable oil, trans fats, high salt content. These increase the risk of cancers, hypertension as well as other health problems.

\section{Microwave Popcorn [8]}

The Microwave Popcorns contain perfluorooctanoic acid (PFOA) and which is a likely carcinogen. The inhalation of vapour of artificial butter present in it which contains dangerous chemicals and can cause lung cancers.

\section{Processed Meats [9]}

Packaged and processed meat, hot dogs, sausages, and other processed meats have been shown to be cancer causing foods, increasing the risk of pancreatic cancer. The hotdogs contain sodium nitrite, a cancer causing ingredient which can increase risk of leukemia 700 times.

\section{Red Meat [10]}

Red meat increases cancer risks. A sugar molecule, called Neu$5 \mathrm{Gc}$, becomes part of your own cells when it's consumed. Your body then attacks it, resulting in inflammation and a higher cancer risk. There is an increase risk of breast cancer among women who consumed more red meat. 


\section{Farmed Salmon [11]}

It is often full of cancer causing contaminants such as pesticides, antibiotics, PCBs, and even flame retardants, making it, one of the cancer causing foods. Opt for the wild salmon instead to get the benefits of Omega-3 fatty acids that salmon provides, without contaminants.

\section{Refined sugar/Soda [12]}

Refined sugar is a danger if obtained from genetically modified sugar beets, because it rapidly spikes insulin levels. Fructose, the type of sugar found in soda, is a serious cancer culprit as well. Soda also contains caramel color, a known carcinogen. Soda acidifies the body, which in turn causes cancer cells to multiply. Skip the sodas and limit intake of refined sugars.

\section{“Diet" Foods [13]}

If we see the words like "diet", "low-fat", "fat-free", or "sugar-free" in the label in the packaged food items and in the canned and bottled beverages we should be beware that these items are loaded with artificial sweeteners e.g. Saccharin, artificial colors and flavors, dyes and more and these additives and colourants may carcinogenic.

\section{Refined White Flour "Maida" [14]}

Table 1: Carcinogenic foods.

\begin{tabular}{|c|c|}
\hline Potential/Status of Food Items & Food Items \\
\hline Carcinogenic to humans & Salted fish \\
\hline Possible carcinogenic to humans & Acetaldehyde and heavy alcohol consumption. \\
\hline Probably carcinogenic to humans & Acrylamide is created in the process of high temperature during cooking of certain foods such as potatoes and \\
cereals.
\end{tabular}

Bleached food may contain traces of the chemicals, the highly processed flours also have a high carbohydrate content which upset the blood sugar balance inside our body and leads to a higher production of insulin and thus feeds cancer cells. Avoid carbohydrates

\section{Genetically Modified Organisms (Gmos)/Glyphosate [15]}

Table 2: Common food items with toxic/dangerous compounds may adulterate during food processing.

\begin{tabular}{|c|c|}
\hline Food Items & Toxic/Dangerous Compounds \\
\hline Hydrogenated Oils & Trans-fats \\
\hline French Fries/Potato Chips & Acrylamide, pesticide residue, trans fats, high salt content \\
\hline Microwave Popcorn & Perfluorooctanoic acid (PFOA), Vapour of artificial butter \\
\hline Processed Meats & $\begin{array}{c}\text { Sodium nitrite, Trans fats, Heterocyclic Amines (HCAs), Polycyclic Aromatic Hydrocarbons } \\
\text { (PAHs), Advanced Glycation End Products (AGEs), Tri-Sodium Phosphate, Excess of } \\
\text { Hydroxynonenal (HNE), Malondialdehyde (MDA), Acrolein, Glyoxal, }\end{array}$ \\
\hline Red Meat & Trimethylamine-N-oxide (TMAO), Neu5Gc \\
\hline Farmed Salmon & Pesticides, Antibiotics, Polychlorinated biphenyl (PCBs) \\
\hline Refined Sugar/Soda & Refined sugar, Fructose, Excess Bicarbonates \\
\hline "Diet" Foods & Saccharin, Artificial colours and Flavors, Dyes \\
\hline Refined White Flour "Maida" & Absence of fibres and Roughage \\
\hline Genetically modified organisms (GMOs)/Glyphosate & Pesticides or Heavy metals \\
\hline
\end{tabular}

Genetically modified organisms (GMOs) have made their way into the majority of our foods. These GMO foods have been modified to withstand heavy doses of a pesticide called glyphosate OR are engineered to contain a toxin that kills bugs. The GMOs foods shown to cause rapid tumour growth and has been linked to Non-Hodgkin's Lymphoma, birth defects, intestinal discomfort, among other things. The only way to avoid GMOs and pesticides is to choose foods that are certified organic label (Table 2). that are highly processed such as white bread, white pasta, white rice, soda \& concentrated fruit juices to avoid this reaction in your body (Table 1).

\section{Safe and Healthy Food Items [16-18]}

A. Food items made up of whole grains, grain flours of wheat, rice, bengal-grams, green-grams, pulses, ragi, oat and many more grains that are locally available.

B. Roasted grains e.g. Bengal-grams

C. Roasted parboiled rice 
D. DALIA (broken/cracked wheat) and KHICHDI (rice \& pulses) recipe

E. Germinated grains e.g. Bengal grams, green-grams

F. Fresh, clean, decontaminated and raw/cooked seasonal vegetables, potatoes, tomatoes, spinach, fenugreek leaves, peas, beat-roots, carrots, coriander leaves and many more vegetables that are locally available

G. Fresh, clean, decontaminated fruits guava, mango, papaya and many more seasonal fruits that are locally available.

H. Fresh prepared fruit juices of orange, mosambi (Citrus limon), pomegranate etc.

I. Milk and milk products preferable fresh pasteurized items e.g. curd, whey, paneer

J. Non-vegetable foods e.g. fresh eggs, chicken and fish

K. Dry fruits, peanuts, cashew-nuts

L. Pure country-made fats and vegetable oils from mustard and others locally available seeds

M. Locally cultivated/home-made spices e.g. cumin, fenugreek seeds, coriander/seeds/powder, ginger, turmeric, chilies, caraway, fennel flower, ajwain etc.
N. Iodized salts
O. Safe drinking water with TDS range 50 to 100
P. Thandai recipe, shikanji/shikanjbi/shikanjbeen/lim- un-paani/nimbu (lemon, sugar \& salt water)
Q. Jaggery, Chikki (jiggery \& peanuts), Laddoo (balls of puls- es and sugar) recipe

\section{"Better to Avoid" Food Items [19]}

a. Potato chips, potato-snacks e.g. Aaloo-Chaat (spicy potatoes), Aaloo-Tikki (potatoes bread), Samosa (fine wheat flour and potatoes)

b. Noodles of various brands available in the market

c. Tea and coffee

d. Biscuits

e. Besan (Bengal gram or red gram flour)-Vegetables-Pakoda, Papad (pulses fried bread)

f. Breads, pav-bhaji (bread and vegetables) and Rusk

g. Chocolates, toffees

\section{Should not be eaten/taken foods [20-22]}

Burger, Chowmein, Pizza, Petties, Pestries, Momos, Pape, Cold drinks, fruit drinks, canned, tetra packed drinks, alcohol, beers and other alcoholic beverages.

\section{Foods that can kill humans if eaten enough $[22,23]$}

A. Rhubarb leaves contain oxalic acid in high concentrations after intake of a little bit of it will burn the mouth, throat, and stomach and too much intake can cause convulsions and then death.

B. Cherry pits and seeds from related fruits, including peaches, plums, almonds, pears, and apricots, contain cyanogenic glycosides and too much intake can cause death.

C. The Ackee fruit contains both hypoglycin A and hypoglycin B Hypoglycin A is the toxin primarily responsible for causing Jamaican vomiting sickness. The exact mechanism of hypoglycin A is not known; however, hypoglycemia most likely results from the inhibition of gluconeogenesis.

D. Castor beans and castor oil contain ricin, present in cosmetics and lotions which is incredibly toxic to humans and if eaten in large quantity can be fatal [2].

E. Wild elderberries the glycosides in the stems, leaves, and juice turn into cyanide in the digestive tract and are fatal to humans.

F. Raw, wild, bitter almond and

G. Raw lima beans are also fatal due to the same reasons as they also release hydrogen cyanide.

H. Nutmeg is the seed or ground spice of several species of the Myristica genus are dangerous and fatal to humans.

I. Cinnamon is not dangerous but when eaten in huge quantities it may be dangerous.

J. Peanuts and shellfish can cause allergies to the certain persons which can be lethal.

K. Potatoes contains glycoalkaloids Glycoalkaloids occur naturally in potatoes and are toxic to humans at high levels can be found in the leaves, stems, and sprouts of potatoes. Eating glycoalkaloids will lead to cramping, diarrhea, confused headaches, or even coma and death.

L. Naturally unpasteurized honey often contains grayanotoxin That can lead to dizziness, weakness, excessive sweating, nausea, and vomiting.

M. The stems and leaves of tomatoes contain alkali poisons that can cause stomach agitation. Unripe green tomatoes have been said to have the same effect.

N. The danger in tuna is the mercury that the fish absorbs. Once in your body, mercury will either pass through your kidneys, or travel to your brain and supposedly drive you insane.

O. The leaves and roots of cassava are surprisingly rich in cyanide.

P. Raw cashews contains the urushiol, a chemical also found in poison ivy, high levels of urushiol can supposedly prove fatal.

\section{Common food items and respective adulterants [24]}

a. Milk in India adulterated with diluted water, detergent, fat and even urea. 
b. Turmeric: coloured saw dust, lead chromate, chalk powder, yellow soap stone powder, turmeric powder can also be adulterated with 'metanil yellow' which is produced with utilizing some raw materials like 'metanilic acid' and 'diphenylamine' and risks of consuming turmeric powder mixed with 'metanil yellow' is its carcinogenic nature means it is capable of causing cancer in living tissues.

c. Chillies powder: Brick powder, salt powder or talc powder

d. Honey is often adulterated with water, table sugar and antibiotics,

e. Black pepper adulterant is Papaya seeds can cause serious liver problems and stomach disorders.

f. In ice Cream adulterant is pepperonil, ethylacetate,butraldehyde, emil acetate, nitrate, washing powder, the pepperoil is used as a pesticide and ethyl acetate causes terribble diseases affecting lungs, kidneys and heart.

g. The powdered rice and wheat is usually adulterated with starch.

h. The coffee powder usually adulterated Tamarind seeds, chicory powder can cause diarrhoea, stomach disorders, giddiness and severe joint pains.

i. Tomato sauces can also artificially be made from 'pumpkin pulp', 'sugar', 'non-edible colours and flavours'. And there may be no tomato present in it. These sauces with 'artificial colours and flavours' are highly carcinogenic.

j. Tea leaves are often adulterated with chemicals and additives that add to its aroma or flavour e.g. Prussian blue, Indigo, Graphite (Plumbago), Gypsum etc.

k. In Mustard seeds and mustard oil adulterant is Argemone seeds, Papaya seeds and can cause epidemic dropsy and severe glaucoma.

I. Khoya (Remains after evaporation of milk) and Chhena (Remains of soar milk) are used for the preparation of traditional Diwali sweets, and are often adulterated with starch. To give metallic glistening to the sweets, the silver layers used in the sweets and the silver must be 99.9 per cent pure if it is used in these sweets. However, the silver is relatively expensive so the aluminium is being used as cheaper alternative by many sweet shops owner endangering the life of their customers in India.

While eating food items the possible adulterants should be taken care off as these may be or may contain traces of carcinogenic agents and may cause cancers of various body parts. All above descriptions are based on the regional available food items and variations may be seen on the basis of the geographical regions, cultural preferences, taboos, rituals etc.

\section{References}

1. McPoil TG, Cornwall MW (1994) Relationship between subtalar joint neutral position and rearfoot motion during walking. Foot Ankle Int 15(3): 141-145

2. Payne CB (1998) The past, present, and future of podiatric biomechanics. JAPMA 88(2): 53-63.

3. Lee WE (2001) Podiatric biomechanics. An historical appraisal and discussion of the Root model as a clinical system of approach in the present context of theoretical uncertainty. Clin Podiatr Med Surg 18(4): 555-684.

4. Nigg BM, Nurse MA, Stefanyshyn DJ (1999) Shoe inserts and orthotics for sport and physical activities. Med Sci Sports Exerc 31(Suppl 7): S421-S428.

5. Stacoff A, Reinschmidt C, Nigg BM, Bogert AJ, Lundberg A, et al. (2000) Effects of foot orthoses on skeletal motion during running. Clin Biomech (Bristol, Avon) 15(1): 54-64.

6. Heiderscheit B, Hamill J, Tiberio D (2001) A biomechanical perspective: do foot orthoses work? Br J Sports Med 35(1): 4-5.

7. Jarvis HL, Nestor CJ, Bowden PD, Jone RK (2017) Challenging the foundations of the clinical model of foot function: further evidence that the root model assessments fail to appropriately classify foot function. Jour of Foot \& Ankle Res 10: 7.

8. Bilanow T (2011) Do orthotics really help?

9. Pine J, Gilmore J (1998) Welcome to the experience economy. Harvard Business Review.

10. Foot Posture Theories. Orthopedia Wiki.

11. Kirby KA (2001) Subtalar joint axis location and rotational equilibrium theory of foot function. J Am Podiatr Med Assoc 91(9): 465-488.

12. Fuller EA, Kirby KA (2013) Subtalar joint equilibrium and tissue stress approach to biomechanical therapy of the foot and lower extremity. In: Albert SF, Curran SA (Eds.), Biomechanics of the Lower Extremity, Theory and Practice, Bipedmed, LLC, Denver, Colorado, USA, 1: 205-264.

13. Kirby K (2015) Prescribing orthoses: Has tissue stress theory supplanted root theory? Podiatry Today 28: 36-44.

14. Kirby KA, Spooner SK, Scherer PR, Schuberth JM (2012) Foot orthoses. Foot \& Ankle Specialist 5(5): 334-343.

15. Shavelson D (2007) A closer look at neoteric biomechanics. Podiatry Today 20(9): 60-66.

16. Root M, Orien W, Weed J (1977) Normal and abnormal function of the foot-Clinical biomechanics, volume 2. Physical Therapy 59(3): 352.

17. Peacock D (2015) The peacock press test. Podiatry Management, pp. 138-144. 


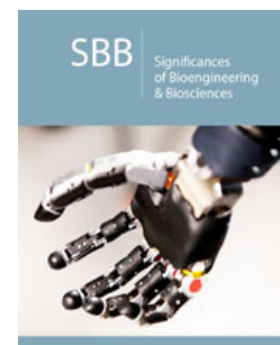

\section{Significances of Bioengineering \& Biosciences}

\section{Benefits of Publishing with us}

- High-level peer review and editorial services

- Freely accessible online immediately upon publication

- Authors retain the copyright to their work

- Licensing it under a Creative Commons license

- Visibility through different online platforms 